\title{
Validation of a novel reconstruction method of laparoscopic gastrectomy for proximal early gastric cancer: a systematic review and meta-analysis
}

\author{
Yixin $\mathrm{Xu}^{1+}$, Jie Gao ${ }^{2+}$, Yibo Wang ${ }^{1}$, Yulin Tan ${ }^{1}$, Cheng $X{ }^{1}$, Nianyuan $\mathrm{Y}^{1}$, Dapeng $\mathrm{Wu}^{3}$ and Xuezhong Xu ${ }^{1 *}$
}

\begin{abstract}
Background: Recently, a novel surgical procedure, named as laparoscopic proximal gastrectomy (LPG) with doubletract reconstruction (DTR), has been reported to provide surgical benefits in the treatment of proximal early gastric cancer (EGC) over traditional laparoscopic total gastrectomy (LTG). These benefits include a lower incidence of some surgical complications and better postoperative nutritional status. However, the number of relevant studies is still too low to validate such benefits. Therefore, this systematic review and meta-analysis aimed to assess the surgical features, complications, and postoperative nutritional status of LPG with DTR in comparison to those of LTG.

Methods: Online databases (PubMed, Web of Science, Cochrane Library, and EMBASE) were scoured for relevant studies published by April 2020. The quality assessment of the included articles was evaluated using the NewcastleOttawa scale. Egger's test was utilized to assess publication bias.

Results: Nine studies (687 patients) were enrolled for this meta-analysis, and we found that LPG with DTR and LTG had similar surgical features. However, LPG with DTR was superior to LTG in the incidence of reflux syndrome $[O R=0.185$; $95 \% \mathrm{Cl} 0.083,0.414 ; P=0.000]$, postoperative nutritional status (hemoglobin $[\mathrm{WMD}=-2.326 ; 95 \% \mathrm{Cl}-4.491,-0.160 ; P$ $=0.035]$, vitamin $\mathrm{B} 12[\mathrm{WMD}=-13.072 ; 95 \% \mathrm{Cl}-22.850,-3.294 ; P=0.009]$, and body weight [WMD $=-3.514 ; 95 \% \mathrm{Cl}$ $-5.579,-1.449 ; P=0.001])$.
\end{abstract}

Conclusions: LPG with DTR has better performance in the incidence of reflux syndrome and postoperative nutritional status compared with LTG. This surgical procedure may therefore have more benefits for patients with proximal EGC.

\section{Introduction}

In 2018 alone, gastric cancer (GC) had approximately 1 million new cases and 800,000 deaths, implying 1 in 10 cancer cases and deaths [1]. Meanwhile, the incidence of proximal early gastric cancer (EGC) in both developed and developing countries has continued to rise $[2,3]$. The

\footnotetext{
* Correspondence: xxz197001@sina.com

${ }^{+}$Yixin Xu and Jie Gao contributed equally to this work.

'Department of General Surgery, Changzhou Wujin People's Hospital

Affiliated to Jiangsu University, The Wujin Clinical College of Xuzhou Medical University, Changzhou, Jiangsu Province, China

Full list of author information is available at the end of the article
}

optimum therapeutic method for proximal EGC is surgery. With the current advances in medical technology, almost all abdominal surgery can be performed using laparoscopy.

The laparoscopic surgical procedures for proximal EGC usually include laparoscopic proximal gastrectomy (LPG) and laparoscopic total gastrectomy (LTG).

The reconstruction method of conventional LPG is esophagogastrostomy, which is often associated with serious postoperative complications, including anastomotic stenosis and reflux syndrome [4]. Therefore, LTG with Roux-en-Y esophagojejunostomy is the preferred surgical procedure for proximal EGC [5]. 
The reconstruction method of LTG is shown in Fig. 1a [6]. However, LTG still has several disadvantages, including food intake restriction and longterm malnutrition (anemia caused by vitamin B12 deficiency and low body weight). Due to these shortcomings, patients who have undergone LTG may suffer low quality of life (QOL), especially for those with relatively long survival time.

A novel reconstruction method of LPG, termed double-tract reconstruction (DTR), has recently emerged. Figure $1 \mathrm{~b}$ details the DTR procedure which has three anastomoses, including esophagojejunostomy (E-J stomy), jejunogastrostomy (J-G stomy), and jejunojejunostomy (J-J stomy). The procedure of E-J stomy is similar to that of LTG. The distances of E-J stomy to JG stomy and J-G-stomy to J-J stomy are usually $15 \mathrm{~cm}$ and $20 \mathrm{~cm}$, respectively. Theoretically, the remnant stomach should be able to overcome problems such as food intake restriction, and deficiency of vitamin B12 and iron. Meanwhile, the interposed jejunum between E-Jstomy and J-Gstomy can alleviate the reflux syndrome problem.

Since its adoption, LPG with DTR has been constantly compared with LTG in postoperative complications and clinical outcomes. Whether LPG with DTR or LTG offers a better therapeutic value for patients with proximal EGC remains controversial until now. Therefore, we sought to assess the surgical features and clinical outcomes between LPG with DTR and LTG.

\section{Methods}

\section{Literature search strategy}

A systematic literature search for studies comparing the surgical features and clinical outcomes between LPG with DTR and LTG was conducted online. Keywords, such as (laparoscopic) and (proximal) and ("double tract" or "double-tract" or "two tract" or "two-tract") and (total) and (gastrectomy), were used to search databases including PubMed, Web of Science, Cochrane Library, and EMBASE for relevant articles published by April 30, 2020.

The full articles were carefully reviewed and we subsequently screened bibliographies of the retrieved articles to identify any potential source of relevant studies.

\section{Study selection}

The inclusion criteria included (1) studies included proximal EGC (clinical stage I); (2) patients underwent either LPG with DTR or LTG; (3) patients were categorized into two groups (LPG with DTR or LTG); and (4) surgical features and/or clinical outcomes (postoperative complications and/or nutritional status) were presented. The exclusion criteria included (1) the types of articles were reviews, letters, comments, and case reports; (2) precise data were unavailable in the articles; and (3) animal studies and non-English publications.

\section{Data extraction and quality assessment}

Two independent researchers (Wang and Tan) extracted the data. The information from enrolled studies included the author information, sample size, surgical features, and elements of clinical outcomes. Moreover, in case of any disagreement between the two reviewers, a third investigator $(\mathrm{Xi})$ would adjudicate.

All continuous data would be converted into mean with standard deviation [7] and analyzed using weighted mean differences (WMD) with 95\% confidence intervals (CIs) intervals. However, the dichotomous data were measured using odds ratios (ORs).

The quality of the included studies (cohort or casecontrol) was assessed using the Newcastle-Ottawa scale (NOS). The NOS evaluates studies using a scale from 0 to 9 , and studies that scored $>6$ were considered high quality [8].
A

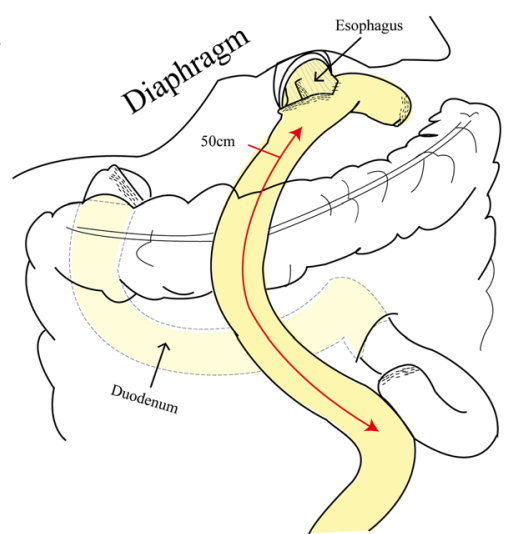

B

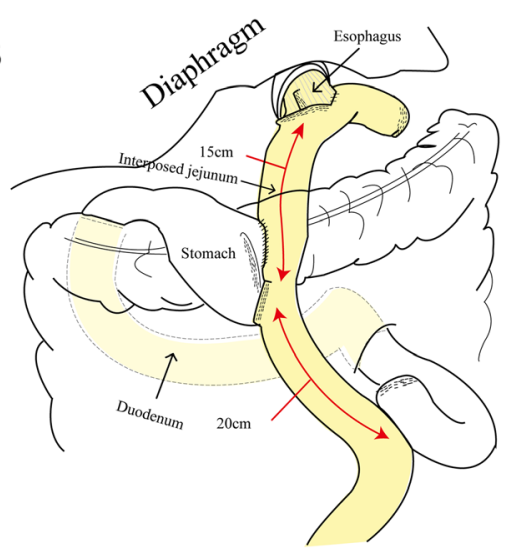

Fig. 1 Schema of reconstruction. a Laparoscopic total gastrectomy with Roux-en-Y esophagojejunostomy. b laparoscopic proximal gastrectomy with double-tract reconstruction 


\section{Outcomes of interest}

The surgical features were initially evaluated between two groups, before assessing the postoperative complications and nutritional status (1 year postoperatively).

\section{Statistical analysis}

Heterogeneity between studies was tested using Cochran $Q$, whereas Higgins' $I^{2}$ statistics were used to assess heterogeneity among studies [9]. If the value of $I^{2}$ was more than $50 \%$, and the $P<0.05$, indicating the existence of significant heterogeneity, then a random-effect model was selected. Otherwise, a fix-effect model would be chosen. If the heterogeneity of included studies was considered significant (higher than 50\%), a sensitivity analysis would be carried out to identify the source of heterogeneity. Additionally, the Egger's test was used to assess the publication bias. Statistical significance was set at $P<0.05$. STATA version 14.0 was used to perform all the meta-analyses.

\section{Results}

\section{Search strategy}

Sixty-nine articles were identified including 20 in PubMed, 6 in Web of Science, 8 in Cochrane Library, and 35 in EMBASE. Forty-one articles were identified as duplicates and were removed after screening. Twenty-six articles were excluded, including non-English journals, case reports, or analyses. Those with imprecise data, varying grouping standards, and irrelevant subjects were similarly omitted. Eventually, nine articles were included in the present meta-analysis (Fig. 2).

\section{Cohort characteristics and quality of the studies}

Nine studies eventually enrolled in the present metaanalysis [6, 10-17] are from Asian countries, i.e., 5 in Korea, 3 in Japan, and 1 in China. All studies provided surgical features and complications, while 6 provided postoperative nutritional status. One article got a NOS score of 6,5 received a NOS score of 7 , and 3 scored 8 , respectively. Two studies were prospective cohort studies, and others were retrospective cohort studies. All characteristics of the included studies are shown in Table 1.

\section{Surgical features}

All data on surgical features are shown in Table 2 and Fig. 3.

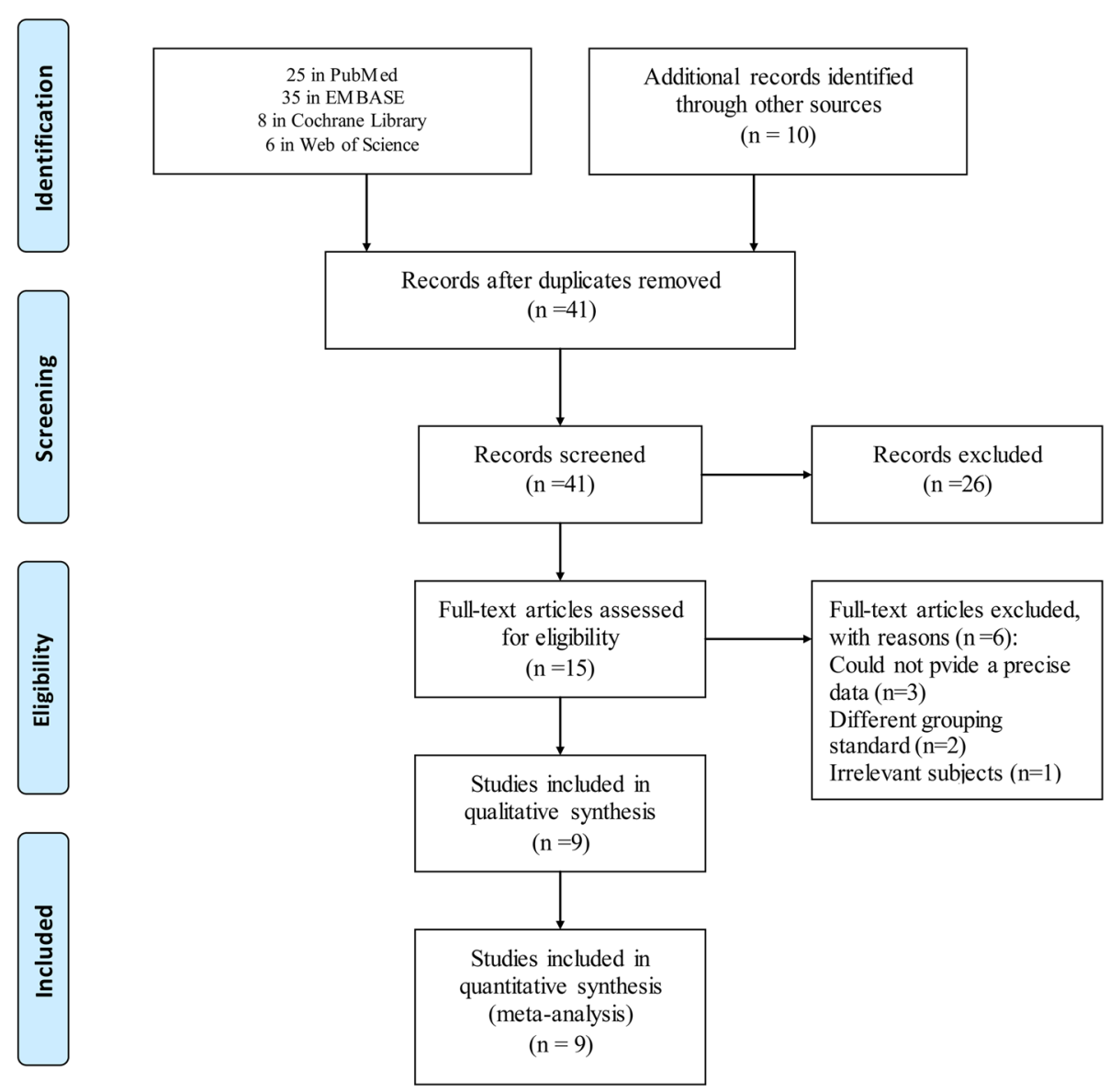

Fig. 2 Flow diagram for study selection 
Table 1 Characteristics of studies included in meta-analysis

\begin{tabular}{|c|c|c|c|c|c|c|c|c|}
\hline Author & Year & Country & $\begin{array}{l}\text { Sample size } \\
\text { (LPG/LTG) }\end{array}$ & Study type & Surgical features reported & Complications reported & $\begin{array}{l}\text { Nutritional status } \\
\text { reported }\end{array}$ & NOS score \\
\hline Park & 2018 & Korea & $34 / 46$ & Retrospective & $\sqrt{ }$ & $\sqrt{ }$ & $\sqrt{ }$ & 8 \\
\hline Aburatani & 2017 & Japan & $19 / 22$ & Retrospective & $\sqrt{ }$ & $\sqrt{ }$ & $\sqrt{ }$ & 7 \\
\hline Nomura & 2018 & Japan & $15 / 30$ & Prospective & $\sqrt{ }$ & $\sqrt{ }$ & $\mathrm{n} / \mathrm{a}$ & 6 \\
\hline Cho & 2018 & Korea & $38 / 42$ & Retrospective & $\sqrt{ }$ & $\sqrt{ }$ & $\sqrt{ }$ & 7 \\
\hline Ahn & 2013 & Korea & $43 / 50$ & Retrospective & $\sqrt{ }$ & $\sqrt{ }$ & $\mathrm{n} / \mathrm{a}$ & 7 \\
\hline Sugiyama & 2018 & Japan & $10 / 20$ & Retrospective & $\sqrt{ }$ & $\sqrt{ }$ & $\sqrt{ }$ & 8 \\
\hline Jung & 2017 & Korea & $92 / 156$ & Retrospective & $\sqrt{ }$ & $\sqrt{ }$ & $\sqrt{ }$ & 7 \\
\hline Kim & 2016 & Korea & $17 / 17$ & Prospective & $\sqrt{ }$ & $\sqrt{ }$ & $\sqrt{ }$ & 8 \\
\hline Wang & 2020 & China & $12 / 24$ & Retrospective & $\sqrt{ }$ & $\sqrt{ }$ & $\mathrm{n} / \mathrm{a}$ & 7 \\
\hline
\end{tabular}

LPG laparoscopic proximal gastrectomy with double-tract reconstruction, LTG laparoscopic total gastrectomy, NOS Newcastle-Ottawa scale

\section{Operation time}

Nine included studies (687 patients) had precise data about the time of operation. The random-effects model was used, due to the significant heterogeneity $\left(I^{2}=\right.$ $80.8 \%, P=0.000)$. There was however no difference between two groups (WMD $=-7.287 ; 95 \%$ CI -21.990 , 7.415; $P=0.331$ ) (Table 2 and Fig. 3a).

\section{Intraoperative blood loss volume}

Eight studies provided data about intraoperative blood loss volume. The difference between two groups was not statistically significant (WMD $=-1.531 ; 95 \%$ CI -25.580 , 22.517; $P=0.901)$. Additionally, the heterogeneity was significant $\left(\mathrm{I}^{2}=74.6 \%, P=0.000\right)$ (Table 2 and Fig. $\left.3 \mathrm{~b}\right)$.

\section{Postoperative hospital stay}

Due to the significant heterogeneity $\left(I^{2}=85.5 \%, P=\right.$ $0.000)$, the random-effects model was used. The result revealed no significant differences between two groups $(\mathrm{WMD}=-1.307 ; 95 \% \mathrm{CI}-2.992,0.378 ; P=0.128)$ (Table 2 and Fig. 3c).

\section{Harvested lymph nodes}

The fixed-effect model was used due to moderate heterogeneity exhibited $\left(I^{2}=50.8 \%, P=0.249\right)$. The result was in favor of the LTG group (WMD $=9.501 ; 95 \%$ CI 7.933, 11.069; $P=0.000$ ) as shown in Table 2 and Fig. $3 \mathrm{~d}$.

\section{Postoperative complications}

The results of postoperative complications are presented in Table 3. Additionally, the forest plots for comparison of reflux syndrome and anastomotic stenosis are shown in Fig. 4a, b.

\section{Overall complications}

Seven studies (601 patients) provided data with significant heterogeneity of overall complications $\left(I^{2}=55.2 \%, P=\right.$ 0.037). However, the incidences of overall surgical complications between two groups were not statistically different $(\mathrm{OR}=0.634 ; 95 \%$ CI 0.334, 1.201; $P=0.162)$ (Table 3$)$.

\section{Analysis of complications by subgroup}

In the subgroup analysis, the differences in the incidences of anastomotic leakage $(\mathrm{OR}=0.783 ; 95 \% \mathrm{CI}$ $0.298,2.060 ; P=0.620)$, pancreatic fistula $(\mathrm{OR}=$ 0.562 ; $95 \%$ CI $0.211,1.499 ; P=0.250)$, and anastomotic stenosis $(\mathrm{OR}=0.604 ; 95 \%$ CI $0.269,1.357 ; P$ $=0.222$ ) were not statistically significant.

Conversely, the incidence of reflux syndrome was significantly higher in the LTG group $(\mathrm{OR}=0.185$; $95 \%$ CI 0.083 , $0.4146 ; P=0.000)$. Based on the moderate heterogeneity $\left(I^{2}\right.$ $=32.2 \%, P=0.207)$, the fixed-effects model was used.

\section{Postoperative nutritional status}

To assess the postoperative nutritional status between LPG with DTR and LTG, the decreased rate of seven variables measured preoperatively and 1 year after surgery

Table 2 Meta-analysis results of surgical features

\begin{tabular}{|c|c|c|c|c|c|c|c|c|c|}
\hline \multirow[t]{2}{*}{ Measured outcome } & \multirow[t]{2}{*}{ Studies } & \multirow[t]{2}{*}{ Patients } & \multirow[t]{2}{*}{ WMD } & \multirow{2}{*}{\multicolumn{2}{|c|}{$95 \% \mathrm{Cl}$}} & \multirow[t]{2}{*}{$P$} & \multicolumn{2}{|c|}{ Heterogeneity test } & \multirow[t]{2}{*}{$P>|t|$} \\
\hline & & & & & & & $P^{2}$ & $P$ & \\
\hline Operation time & 9 & 687 & -7.287 & -21.990 & 7.415 & 0.331 & 80.8 & 0.000 & 0.796 \\
\hline Intraoperative blood loss & 8 & 653 & -1.531 & -25.580 & 22.517 & 0.901 & 74.6 & 0.000 & 0.683 \\
\hline PO hospital stay & 9 & 687 & -1.307 & -2.992 & 0.378 & 0.128 & 85.5 & 0.000 & 0.101 \\
\hline Harvested lymph nodes & 6 & 508 & 9.501 & 7.933 & 11.069 & 0.000 & 50.8 & 0.071 & 0.249 \\
\hline
\end{tabular}




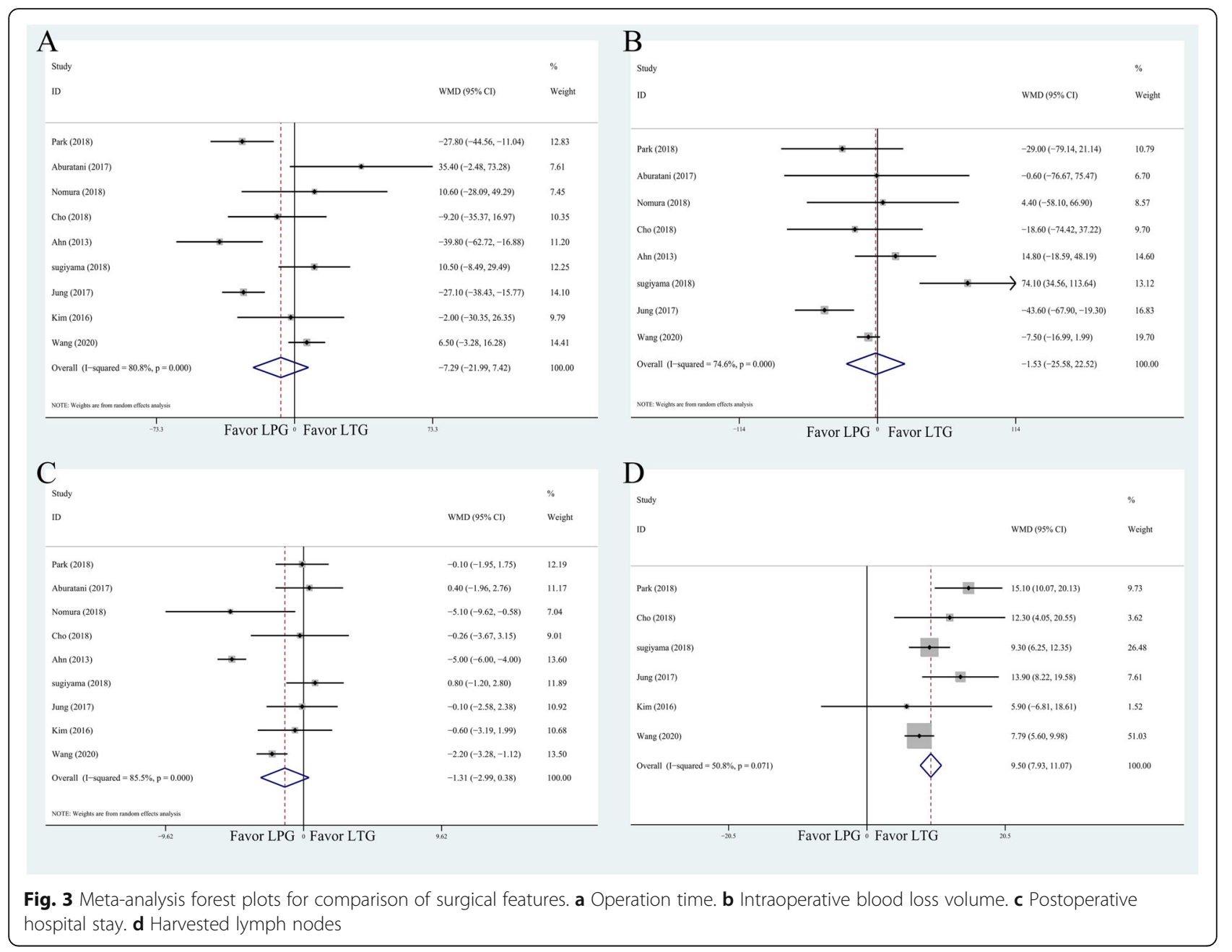

was selected. These variables included albumin, hemoglobin, total protein, vitamin B12, total cholesterol, iron, and body weight loss.

All results of postoperative nutritional status are shown in Table 4. Moreover, the overall effects size of albumin, hemoglobin, vitamin B12, and body weight were shown in Fig. 5.

The overall effects of albumin level, total protein, total cholesterol, and iron did not favor either LPG or LTG groups. However, it showed that hemoglobin, vitamin
B12, and body weight were significantly lower in LTG group (Table 4).

\section{Publication bias and sensitivity analysis}

The publication bias was assessed in every element using Egger's test, but no publication bias was revealed. Similarly, no studies with potential heterogeneity were revealed from the Galbraith plot, used to measure heterogeneity.

Table 3 Meta-analysis results of postoperative complications

\begin{tabular}{|c|c|c|c|c|c|c|c|c|c|}
\hline \multirow[t]{2}{*}{ Measured outcome } & \multirow[t]{2}{*}{ Studies } & \multirow[t]{2}{*}{ Patients } & \multirow[t]{2}{*}{ OR } & & \multirow[t]{2}{*}{$95 \% \mathrm{Cl}$} & \multirow[t]{2}{*}{$P$} & \multicolumn{2}{|c|}{ Heterogeneity test } & \multirow[t]{2}{*}{$P>|t|$} \\
\hline & & & & & & & $\bar{R}$ & $P$ & \\
\hline Overall complications & 7 & 601 & 0.634 & 0.334 & 1.201 & 0.162 & 55.2 & 0.037 & 0.636 \\
\hline Anastomotic leakage & 6 & 480 & 0.783 & 0.298 & 2.060 & 0.620 & 0.0 & 0.764 & 0.352 \\
\hline Pancreatic fistula & 5 & 450 & 0.562 & 0.211 & 1.499 & 0.250 & 13.3 & 0.326 & 0.341 \\
\hline Reflux syndrome & 5 & 450 & 0.185 & 0.083 & 0.414 & 0.000 & 32.2 & 0.207 & 0.169 \\
\hline Anastomotic stenosis & 7 & 571 & 0.604 & 0.269 & 1.357 & 0.222 & 11.1 & 0.345 & 0.513 \\
\hline
\end{tabular}




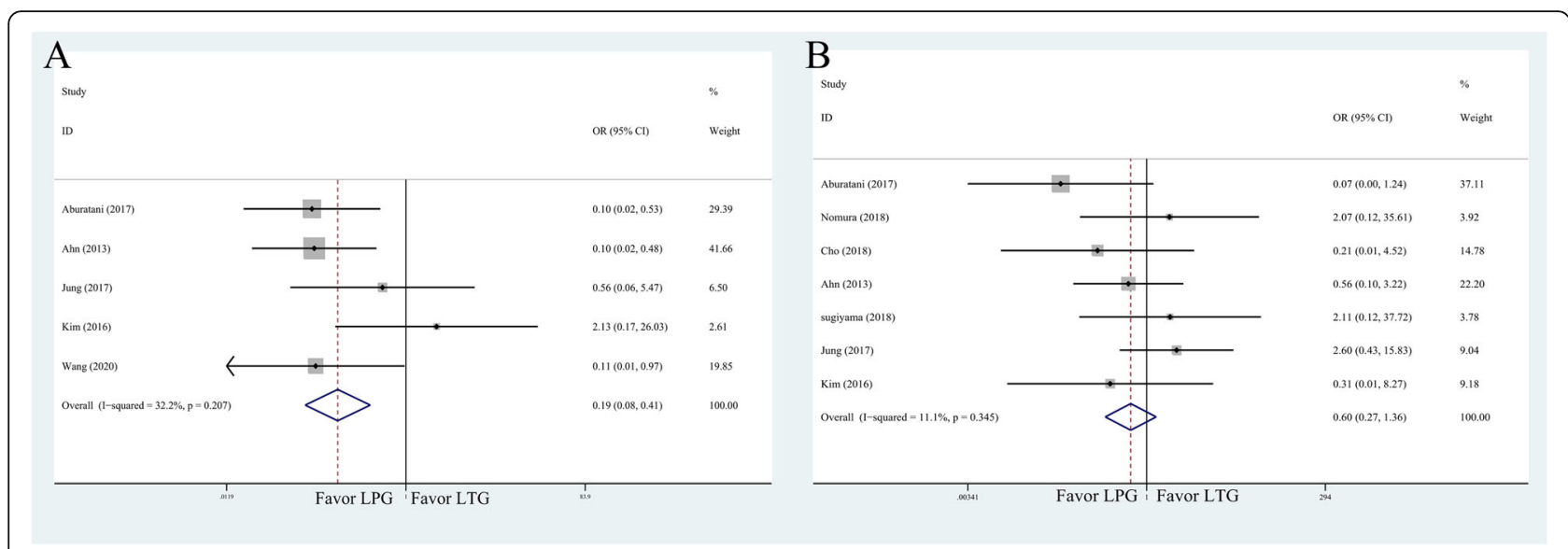

Fig. 4 Meta-analysis forest plots for comparison of postoperative complications. a Reflux syndrome. b Anastomotic stenosis

\section{Discussion}

With the advancements of endoscopic technology, several physicians prefer to treat patients with proximal EGC. The endoscopic therapeutic procedures for proximal EGC mainly include endoscopic mucosal resection (EMR) and endoscopic submucosal dissection (ESD) [18, 19]. However, both of them have their respective limitations. For example, EMR is only recommended for the treatment of ulcer-free EGC, which should be less than $20 \mathrm{~mm}$ in diameter [20]. However, the incidence of lymph node metastasis of lesions limited to mucosa varies from 3 to $5 \%$. Meanwhile, the incidence increases to $16-25 \%$ for those lesions deep into submucosa [21-23]. Due to the relatively high risk of lymph metastasis, the optimal therapeutic method for proximal EGC is still curative gastrectomy, which includes LPG and LTG [24-26]. Although the conventional LPG is considered more function-preserved, surgeons prefer LTG over LPG due to the severe postoperative complications (anastomotic stenosis and reflux syndrome) caused by the reconstruction method of esophagogastrostomy [27, 28]. The common surgical procedure for proximal EGC patients is therefore LTG. However, LTG is far from satisfactory. Besides, patients who have undergone LTG often exhibit several symptoms such as low body weight, anemia, food intake restriction, diarrhea, and dumping [29, 30]. Recently, surgeons have been gradually accepting LPG with DTR as it is thought to overcome the shortcomings of conventional LPG and LTG [14, 31]. However, there are still controversies about which surgical procedure is the best choice for proximal EGC patients.

There are three elements of optimal surgical procedure that should be considered before deciding. These include oncological safety, anastomosis-related complications, and functional benefits.

First, oncological safety means the lymphadenectomy technique, the margin of resection and the quantity of the lymph nodes (LNs) retrieved. The clinical diagnosis of EGC is not quite accurate due to some technical constraints. Occasionally, lymph nodes metastasis occurs in patients diagnosed with EGC. Lee et al. reported that of 1308 patients with clinical EGC, 93 patients had group 1 and 33 had group 2 lymph node metastasis. Extended lymphadenectomy is recommended for EGC patients with tumor located in the proximal third of the stomach [32]. However, patients who underwent LPG with DTR always received D1+ lymphadenectomy. The data

Table 4 Meta-analysis results of postoperative nutritional status

\begin{tabular}{|c|c|c|c|c|c|c|c|c|c|}
\hline \multirow{2}{*}{$\begin{array}{l}\text { Measured } \\
\text { outcome }\end{array}$} & \multirow[t]{2}{*}{ Studies } & \multirow[t]{2}{*}{ Patients } & \multirow[t]{2}{*}{ OR } & \multirow{2}{*}{\multicolumn{2}{|c|}{$95 \% \mathrm{Cl}$}} & \multirow[t]{2}{*}{$P$} & \multicolumn{2}{|c|}{ Heterogeneity test } & \multirow[t]{2}{*}{$P>|t|$} \\
\hline & & & & & & & P & $P$ & \\
\hline Albumin & 6 & 513 & 0.139 & -0.282 & 0.560 & 0.517 & 78.6 & 0.000 & 0.688 \\
\hline Hemoglobin & 6 & 513 & -2.326 & -4.491 & -0.160 & 0.035 & 95.3 & 0.000 & 0.344 \\
\hline Total protein & 6 & 513 & 0.462 & -0.664 & 1.588 & 0.422 & 55.1 & 0.000 & 0.209 \\
\hline Vitamin B12 & 4 & 442 & -13.072 & -22.850 & -3.294 & 0.009 & 90.4 & 0.000 & 0.771 \\
\hline Cholesterol & 4 & 449 & -0.610 & -5.863 & 4.644 & 0.820 & 49.0 & 0.000 & 0.927 \\
\hline Iron & 3 & 194 & 3.000 & -25.634 & 31.634 & 0.837 & 56.8 & 0.000 & 0.958 \\
\hline Body weight & 6 & 537 & -3.514 & -5.579 & -1.449 & 0.001 & 89.8 & 0.000 & 0.870 \\
\hline
\end{tabular}




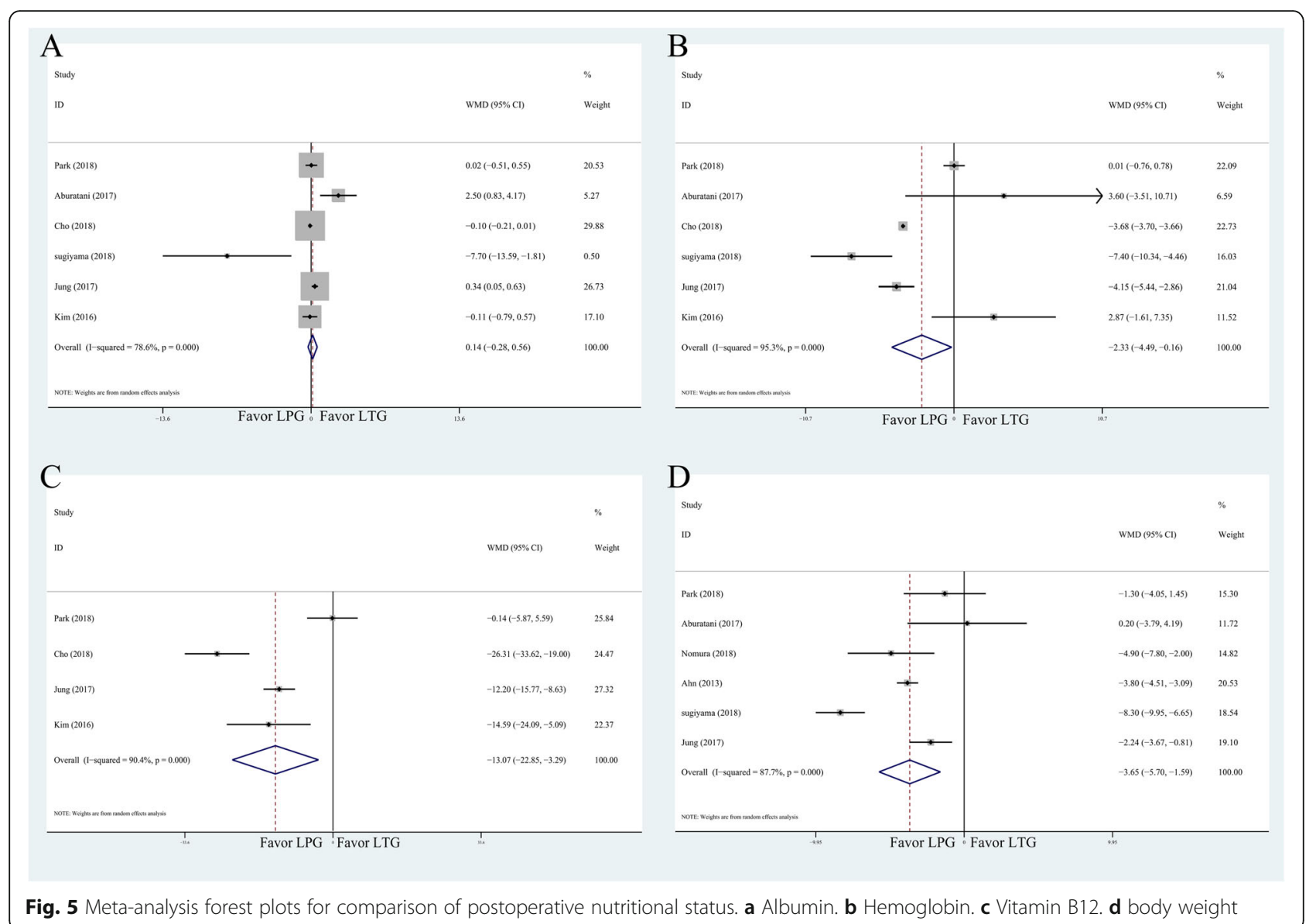

provided by six articles enrolled in the present study on the quantity of retrieved LNs, favored the LTG group. Hence, the probability metastatic lymph nodes being missed in patients undergoing LPG with DTR is relatively higher. To compensate for this disadvantage, precise clinical diagnosis or more radical procedure may be needed to prevent missed diagnosis of patients with lymph node metastasis.

Secondly, the aim of performing LPG for proximal EGC patients is to preserve the gastric reservoir with its secretory function [33]. The conventional reconstruction method of LPG is direct esophagogastrostomy, which is simple and requires only one anastomosis. However, this kind of anastomosis means the loss of the lower esophageal sphincter and the acute angle of the lesser curvature. Moreover, it may cause severe anastomosis-related complications, reflux syndrome, and anastomotic stenosis [34]. There are several anti-reflux and anti-stenosis procedures, including fundoplication, gastric tube formation, pyloroplasty, and esophagopexy with a crural repair. However, these methods are unfavorable because they all employ esophagogastrostomy; the primary cause of reflux and stenosis $[35,36]$.
Fortunately, there is a better alternative reconstruction method, Roux-en-Y type E-Jstomy. This effective method of reconstruction involves performing either DTR or jejunal interposition, following LPG. Although jejunal interposition is widely accepted by surgeons in the open surgery, its standard procedure includes three anastomoses and the formation of a pedicled jejunal flap. It is therefore considered to be technically complex and has not yet been accepted in laparoscopic surgery [37].

Secondly, in the procedure of DTR, the distance from esophagojejunostomy (E-Jstomy) to gastrojejunostomy (G-Jstomy) varies with the habits of the surgeon. For example, Ahn had reported $10 \mathrm{~cm}$ and Nomura reported $15 \mathrm{~cm}[11,14]$. Jung et al. found that the incidence of reflux syndrome was rather high when the length of the interposed jejunum was $10 \mathrm{~cm}$ [12]. Theoretically, the incidence of reflux syndrome decreases as the length of interposed jejunum increases. But it has already been proven that the length of over $20 \mathrm{~cm}$ is not associated with a lower rate of reflux syndrome $[38,39]$. As a result, the optimal distance from E-Jstomy to G-Jstomy could be $15 \mathrm{~cm}$.

Our findings revealed that the surgical features of LPG with DTR were not statistically different from those of 
LTG, indicating that the technical complexities between both procedures are comparable. Moreover, the incidence of reflux syndrome was significantly lower in LPG with DTR group. This result clearly identified the superiority of DTR in anti-reflux function.

Finally, functional benefits are concentrated mainly on the absorption of vitamin B12 and serum iron, and body weight maintenance. Previous studies have revealed that LPG with DTR performed better than LTG in nutrient absorption function $[10,11,15]$. The main principle is that serum iron absorption is related to the processes of food bypass in the duodenum and proximal jejunum [40]. LPG with DTR maintains the food pathways which could potentially influence the iron metabolism. In the present study, we found that LPG with DTR had superiority of maintenance of hemoglobin, vitamin B12, and body weight.

However, Cho et al. found LPG with DTR, and LTG to have similar long-term nutritional outcomes [6]. Ahn et al. showed that in the reconstructed digestive tract of patients who underwent LPG with DTR, only $60 \%$ of food intake went through the remnant stomach, while the other passed directly into the jejunum [11]. Such a quantity of food intake through remnant stomach into duodenum is not sufficient to prevent iron deficiency. In addition, the less oral intake caused by the smaller volume of the remnant stomach after gastrectomy may also affect iron deficiency. Iron deficiency was also observed following distal subtotal gastrectomy, which fully preserves the digestive tract from remnant stomach to duodenum [41]. Therefore, the preservation of distal stomach may be insufficient to prevent iron deficiency.

Vitamin B12 metabolism is significantly affected by the secretion of intrinsic factor released from gastric parietal cells. Besides, gastric parietal cells are basically located in the body of the stomach, much of which may be removed after LPG. Moreover, bile reflux or other cellular pathological changes can also affect the remaining parietal cells [42]. The deficiency of vitamin B12 after the procedure of LPG with DTR may be inevitable. Therefore, further work should determine the optimal surgical procedure is the optimal choice in preserving nutritional function. In the LPG with DTR, the development of remnant gastric cancer is a serious concern. Besides, the incidence of the remnant gastric cancer after LPG is reported to range between 5 and $5.4 \%$ [43], compared to $0.4-2.9 \%$ after distal gastrectomy [44]. This could be attributed to the relatively high incidence of cancer development in distal stomach. Therefore, the routine endoscopic examination is strongly recommended for patients who have undergone LPG with DTR. Although it is technically difficult to examine the remnant distal stomach, a previous article reported three intubation failures occurred among 43 patients underwent LPG with DTR [11]. However, it is possible for endoscopists to examine the remaining distal stomach after the surgeons have explained the specific DTR procedure. Thus, the regular and repeated communication between endoscopists and surgeons is critical for endoscopic surveillance for patients after undergoing LPG with DTR.

This study had the following limitations. First, patients enrolled in the present study were of different nationalities and had different physical histories. This would result in a significant selection bias. Secondly, the sample size of the included studies is relatively small, which could make our findings unreliable. Finally, although we searched the databases very carefully, articles from western countries were not found. Selection bias may, therefore, exist in our findings as all included studies were from Asia.

\section{Conclusion}

The surgical features in both LPG with DTR and LTG groups are comparable, which translates to similar technical complexity. Although some advantages still need to be confirmed, LPG with DTR is superior to LTG with reference to reflux syndrome incidence and preservation of nutritional function (hemoglobin, vitamin B12, and body weight). For patients with proximal EGC, LPG with DTR may be used as a valuable surgical procedure.

\section{Abbreviations \\ Cl: Confidence interval; DTR: Double-tract reconstruction; ESD: Endoscopic submucosal dissection; EGC: Early gastric cancer; EMR: Endoscopic mucosal resection; E-Jstomy: Esophagojejunostomy; GC: Gastric cancer; G- \\ Jstomy: Gastrojejunostomy; HR: Hazard ratio; J-Jstomy: Jejunojejunostomy; LN: Lymph node; LPG: Laparoscopic proximal gastrectomy; LTG: Laparoscopic total gastrectomy; OR: Odds ratio; NOS: Newcastle-Ottawa scale; QOL: Quality of life; WMD: Weighted mean differences}

\section{Acknowledgements}

We thank Dr. Peng Jiang and Dr. Haifeng Tang for their critical reading and informative advice during the process of study.

\section{Authors' contributions}

Conceptualization: Yixin Xu, Jie Gao. Validation: Yibo Wang, Yulin Tan, Dapeng Wu. Visualization: Cheng Xi, Nianyuan Ye. Writing-original draft: Yixin Xu, Jie Gao. Writing-review and editing: Xuezhong Xu. The author(s) read and approved the final manuscript.

Funding

There is no funding resource.

\section{Availability of data and materials}

All the data comes from databases. The author has sorted out all the data and attached to the attachment at the end of the articles.

\section{Ethics approval and consent to participate}

This research is a meta-analysis of published studies that did not need informed consent. Ethics approval and consent to participate were not applicable in this study.

\section{Consent for publication}

Consent for publication was not necessary, as this study was a "systematic review and meta-analysis." There are no any individual person's data in any form in this article. 


\section{Competing interests}

No potential conflicts of interest were disclosed.

\section{Author details}

'Department of General Surgery, Changzhou Wujin People's Hospital Affiliated to Jiangsu University, The Wujin Clinical College of Xuzhou Medical University, Changzhou, Jiangsu Province, China. ${ }^{2}$ Department of General Surgery, Kunshan Traditional Chinese Medicine Hospital, Kunshan, Jiangsu, China. ${ }^{3}$ Department of Endoscopy, Jiangsu Provincial Hospital of Traditional Chinese Medicine, Nanjing, Jiangsu, China.

\section{Received: 18 May 2020 Accepted: 6 August 2020}

\section{Published online: 18 August 2020}

\section{References}

1. Bray F, Ferlay J, Soerjomataram I, Siegel RL, Torre LA, Jemal A. Global cancer statistics 2018: GLOBOCAN estimates of incidence and mortality worldwide for 36 cancers in 185 countries. CA Cancer J Clin. 2018;68(6):394-424.

2. Ahn HS, Lee HJ, Yoo MW, Jeong SH, Park DJ, Kim HH, et al. Changes in clinicopathological features and survival after gastrectomy for gastric cancer over a 20-year period. Br J Surg. 2011;98(2):255-60.

3. Borch K, Jönsson B, Tarpila E, Franzén T, Berglund J, Kullman E, et al. Changing pattern of histological type, location, stage and outcome of surgical treatment of gastric carcinoma. Br J Surg. 2000;87(5):618-26.

4. Wang $S$, Lin S, Wang H, Yang J, Yu P, Zhao Q, et al. Reconstruction methods after radical proximal gastrectomy: a systematic review. Medicine. 2018; 97(11):e0121.

5. Jeong O, Park Y-K. Clinicopathological features and surgical treatment of gastric cancer in South Korea: the results of 2009 nationwide survey on surgically treated gastric cancer patients. Journal of gastric cancer. 2011; 11(2):69-77.

6. Cho M, Son T, Kim HI, Noh SH, Choi S, Seo WJ, et al. Similar hematologic and nutritional outcomes after proximal gastrectomy with double-tract reconstruction in comparison to total gastrectomy for early upper gastric cancer. Surg Endosc. 2018;10.1007/s00464-018-6448-x.

7. Hozo SP, Djulbegovic B, Hozo I. Estimating the mean and variance from the median, range, and the size of a sample. BMC Med Res Methodol. 2005:5:13.

8. Stroup DF, Berlin JA, Morton SC, Olkin I, Williamson GD, Rennie D, et al. Meta-analysis of observational studies in epidemiology: a proposal for reporting. Meta-analysis of observational studies in epidemiology (MOOSE) group. Jama. 2000;283(15):2008-12.

9. Higgins JPT, Thompson SG, Deeks JJ, Altman DG. Measuring inconsistency in meta-analyses. BMJ. 2003;327(7414):557-60.

10. Aburatani T, Kojima K, Otsuki S, Murase H, Okuno K, Gokita K, et al. Doubletract reconstruction after laparoscopic proximal gastrectomy using detachable ENDO-PSD. Surg Endosc. 2017;31(11):4848-56.

11. Ahn SH, Jung DH, Son SY, Lee CM, Park DJ, Kim HH. Laparoscopic doubletract proximal gastrectomy for proximal early gastric cancer. Gastric Cancer. 2014;17(3):562-70.

12. Jung DH, Lee Y, Kim DW, Park YS, Ahn SH, Park DJ, et al. Laparoscopic proximal gastrectomy with double tract reconstruction is superior to laparoscopic total gastrectomy for proximal early gastric cancer. Surg Endosc. 2017;31(10):3961-9.

13. Kim DJ, Kim W. Laparoscopy-assisted proximal gastrectomy with double tract anastomosis is beneficial for vitamin B12 and iron absorption. Anticancer Res. 2016;36(9):4753-8.

14. Nomura E, Kayano H, Lee SW, Kawai M, Machida T, Yamamoto S, et al. Functional evaluations comparing the double-tract method and the jejunal interposition method following laparoscopic proximal gastrectomy for gastric cancer: an investigation including laparoscopic total gastrectomy. Surg Today. 2019;49(1):38-48.

15. Park JY, Park KB, Kwon OK, Yu W. Comparison of laparoscopic proximal gastrectomy with double-tract reconstruction and laparoscopic total gastrectomy in terms of nutritional status or quality of life in early gastric cancer patients. Eur J Surg Oncol. 2018;44(12):1963-70.

16. Sugiyama M, Oki E, Ando K, Nakashima Y, Saeki H, Maehara Y. Laparoscopic proximal gastrectomy maintains body weight and skeletal muscle better than total gastrectomy. World J Surg. 2018;42(10):3270-6.

17. Wang L, Xia Y, Jiang T, Li F, Wang W, Zhang D, et al. Short-term surgical outcomes of laparoscopic proximal gastrectomy with double-tract reconstruction versus laparoscopic total gastrectomy for adenocarcinoma of esophagogastric junction: a matched-cohort study. J Surg Res. 2020;246: 292-9.

18. Koeda K, Nishizuka S, Wakabayashi G. Minimally invasive surgery for gastric cancer: the future standard of care. World J Surg. 2011;35(7):1469-77.

19. Heydary H, Karamian E, Poorazizi E, Heydaripour J, Khandan A. Electrospun of polymer/bioceramic nanocomposite as a new soft tissue for biomedical applications. Journal of Asian Ceramic Societies. 2015;3(4):417-25.

20. Eguchi T, Gotoda T, Oda I, Hamanaka H, Saito D. Is endoscopic one-piece mucosal resection essential for early gastric cancer? Dig Endosc. 2010;15(2): 113-6.

21. Oñate-Ocaña LF, Aiello-Crocifoglio V, Mondragón-Sánchez R, Ruiz-Molina JM. Survival benefit of D2 lymphadenectomy in patients with gastric adenocarcinoma. Ann Surg Oncol. 2000;7(3):210-7.

22. Gore RM, Levine MS, Ghahremani GG, Miller FH. Gastric cancer. Radiologic diagnosis. Radiol Clin N Am. 1997;35(2):311-29.

23. Khandan A, Jazayeri H, Fahmy M, Razavi M. Hydrogels: types, structure. Properties Appl Biomat Tiss Eng. 2017;4(27):143-69.

24. Ooki A, Yamashita KS. Clinical significance of total gastrectomy for proximal gastric cancer. Anticancer Res. 2008;28(5B):2875.

25. Ichikawa D, Komatsu S, Kubota T, Okamoto K, Shiozaki A, Fujiwara H, et al. Long-term outcomes of patients who underwent limited proximal gastrectomy. Gastric Cancer. 2014;17(1):141-5.

26. Khandan A, Salami M, Kaveian F, Rafienia M, Saber-Samandari S, Naeimi M. Electrospun Polycaprolactone/lignin-based nanocomposite as a novel tissue scaffold for biomedical applications. J Med Sign Sens. 2017;7(4): 228.

27. Wen L, Chen X-Z, Wu B, Chen X-L, Wang L, Yang K, et al. Total vs. proximal gastrectomy for proximal gastric cancer: a systematic review and metaanalysis. Hepatogastroenterology. 2012;59(114):633-40.

28. Pu Y-W, Gong W, Wu Y-Y, Chen Q, He T-F, Xing C-G. Proximal gastrectomy versus total gastrectomy for proximal gastric carcinoma. A meta-analysis on postoperative complications, 5-year survival, and recurrence rate. Saudi Med J. 2013;34(12):1223-8.

29. Takiguchi N, Takahashi M, Ikeda M, Inagawa S, Ueda S, Nobuoka T, et al. Long-term quality-of-life comparison of total gastrectomy and proximal gastrectomy by postgastrectomy syndrome assessment scale (PGSAS-45): a nationwide multi-institutional study. Gastric cancer : official journal of the International Gastric Cancer Association and the Japanese Gastric Cancer Association. 2015;18(2):407-16.

30. Qi J, Zhang $P$, Wang $Y$, Chen H, Li Y. Does total gastrectomy provide better outcomes than distal subtotal gastrectomy for distal gastric cancer? A Systematic Review and Meta-Analysis PLOS ONE. 2016;11: e0165179.

31. Sheikhbahaei E, Kamyab Moghadas B, Joneidi Yekta H, Khandan A, SaberSamandari S, Esmaeili S, et al. A mitral heart valve prototype using sustainable polyurethane polymer: fabricated by 3D bioprinter, tested by molecular dynamics simulation. AUT Journal of Mechanical Engineering. 2020.

32. Lee $\mathrm{HH}$, Yoo HM, Song KY, Jeon HM, Park CH. Risk of limited lymph node dissection in patients with clinically early gastric cancer: indications of extended lymph node dissection for early gastric cancer. Ann Surg Oncol. 2013;20(11):3534-40

33. Norio S, Yosuke A, Seigo K, Kenji K, Masafumi I, Kazuhiro Y. Clinical outcome of proximal versus total gastrectomy for proximal gastric cancer. World J Surg. 2002;26(9):1150.

34. Ji YA, Youn HG, Min GC, Noh JH, Sohn TS, Kim S. The difficult choice between total and proximal gastrectomy in proximal early gastric cancer. Am J Surg. 2008;196(4):587-91.

35. Yeong AJ, Ho Geun Y, Gew CM, Jae Hyung N, Tae Sung S, Sung K. The difficult choice between total and proximal gastrectomy in proximal early gastric cancer. Am J Surg. 2008;196(4):587-91.

36. Yoo CH, Sohn BH, Han WK, Pae WK. Long-term results of proximal and total gastrectomy for adenocarcinoma of the upper third of the stomach. Cancer Research \& Treatment. 2004:36(1):50-5.

37. Kinoshita T, Gotohda N, Kato Y, Takahashi S, Konishi M, Kinoshita T. Laparoscopic proximal gastrectomy with jejunal interposition for gastric cancer in the proximal third of the stomach: a retrospective comparison with open surgery. Surg Endosc. 2013;27(1):146-53.

38. Ping Z. Shuo-Meng, Xiao, Ling-Chao, tang, et al. proximal gastrectomy with jejunal interposition and TGRY anastomosis for proximal gastric cancer. World J Gastroenterol. 2014;20(25):8268-73. 
39. Katai H, Morita S, Saka M, Taniguchi H, Fukagawa T. Long-term outcome after proximal gastrectomy with jejunal interposition for suspected early cancer in the upper third of the stomach. Br J Surg. 2010;97(4):558-62.

40. Fleming RE, Bacon BR. Orchestration of iron homeostasis. N Engl J Med. 2005;352(17):1741-4.

41. Joong Ho L, Woo Jin H, Hyoung-II K, Yoo-Min K, Taeil S, Naoki O, et al. Method of reconstruction governs iron metabolism after gastrectomy for patients with gastric cancer. Ann Surg. 2013;258(6):964-9.

42. Burclaff J, Osaki LH, Liu D, Goldenring JR, Mills JC. Targeted apoptosis of parietal cells is insufficient to induce metaplasia in stomach. Gastroenterology. 2016;152(4):762-6.

43. Ohyama S, Tokunaga M, Hiki N, Fukunaga T, Fujisaki J, Seto Y, et al. A clinicopathological study of gastric stump carcinoma following proximal gastrectomy. Gastric Cancer. 2009;12(2):88-94.

44. Paolo M, Andrea G, Daniele M, Giovanni V, Alberto M, Giovanni DM, et al. Gastric stump carcinoma after distal subtotal gastrectomy for early gastric cancer: experience of 541 patients with long-term follow-up. Am J Surg. 2015;209(6):1063-8.

\section{Publisher's Note}

Springer Nature remains neutral with regard to jurisdictional claims in published maps and institutional affiliations.

Ready to submit your research? Choose BMC and benefit from:

- fast, convenient online submission

- thorough peer review by experienced researchers in your field

- rapid publication on acceptance

- support for research data, including large and complex data types

- gold Open Access which fosters wider collaboration and increased citations

- maximum visibility for your research: over $100 \mathrm{M}$ website views per year

At BMC, research is always in progress.

Learn more biomedcentral.com/submissions 